\title{
Evaluation on the Impact Factors of University Students' English Proficiency Based on AHP
}

\author{
Jian Yong \\ Weihai Vocational University, Shandong, China \\ 1541545319@qq.com
}

Keywords: AHP; University students' English proficiency; Impact factors

\begin{abstract}
To become a qualified international talent, University students must improve their English level. At present, there are so many researches on improving the university students' English level, most of them are about the ranks of teachers, teaching methods, teaching equipment and teaching means, this paper will research from the effect of University Students' English level impact factor to determine first level, second level indicators, establish evaluation system model. We provide reference for university management education, University English teachers and university students.
\end{abstract}

\section{Introduction}

With the development of global economic integration, the requirement of international talents is becoming higher and higher. To become a qualified international talent, university students must improve their English level. At present, there are so many researches on improving the university students' English level, most of them are about the ranks of teachers, teaching methods, teaching equipment and teaching means, this paper will research from the effect of University Students' English level impact factor to determine first level, second level indicators, establish evaluation system model, by using analytic hierarchy process, and establish judgment matrix, then calculate results and check consistency, finally draws the conclusion. We provide reference for university management education, University English teachers and university students.

\section{Model Construction of University Students' English Proficiency}

For the influential factors of university students' English level, the author gave 300 questionnaires to university English teachers and university students, and recycled 294. Survey university students English level influence factors, compute statistics, finally determine the impact factors of university students English level, second level indicators.

The primary indicators of influencing factors of University Students' English proficiency includes English basis, teaching staff, teaching methods and learning methods.

In the two level indicator:

English basis includes listening, speaking, reading and writing.

Teaching staff includes experience strength, moral character, professional knowledge, physical and psychological quality.

Teaching methods includes writing teaching, multimedia teaching, case teaching, group discussion.

Learning methods includes positive learning, cooperative learning, inquiry learning

Teaching contents includes teaching objectives, teaching difficulties, teaching methods, teaching steps.

Political accomplishment includes love motherland, political belief, political learning, theoretical level. 


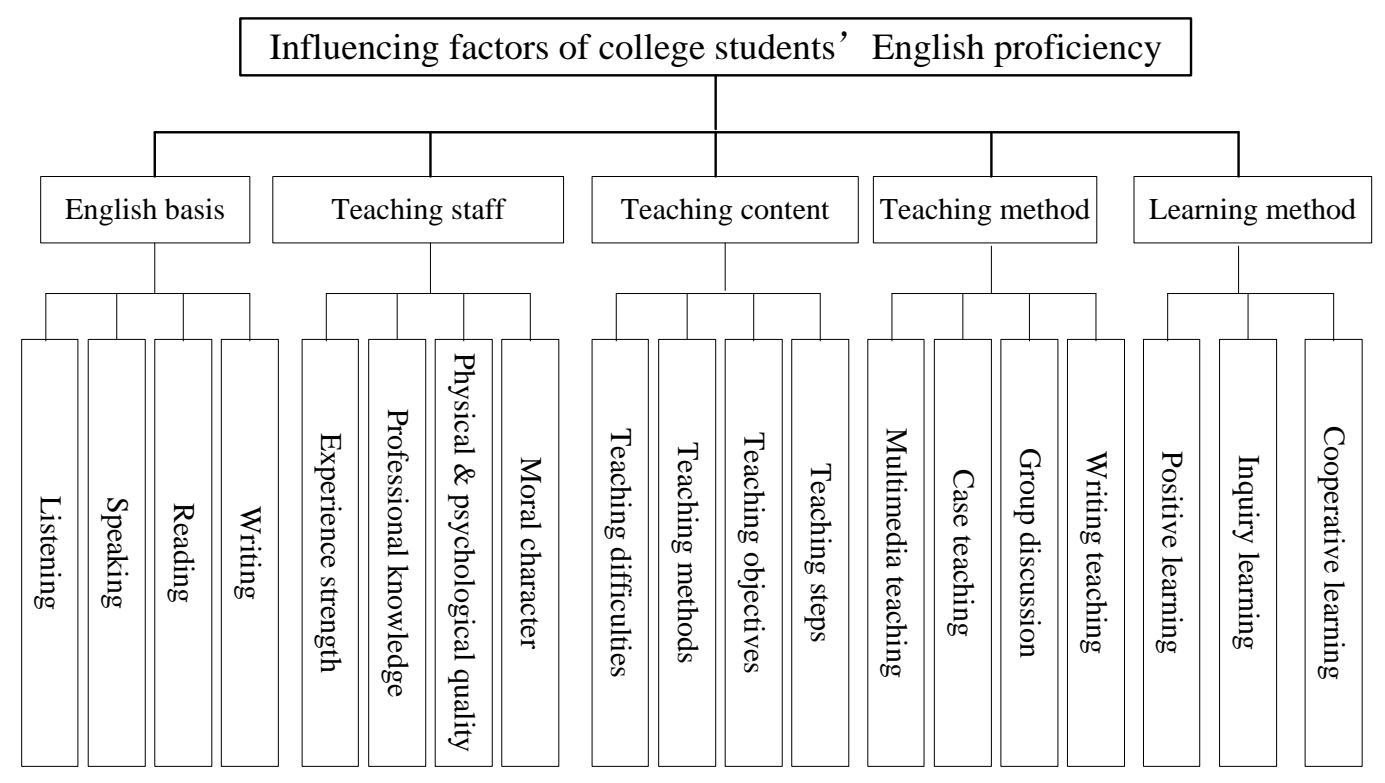

Figure 1. University Students' English level impact factors

\section{Analytic Hierarchy Process}

The analytic hierarchy process is to decompose the elements which are always related to the decision, the target, the criterion, the plan and so on, and then make the qualitative and quantitative analysis. At first, establish the model, and then construct the judgment matrix, make the level of single row and test consistency finally.

The first class comparison matrix:

$\left[\begin{array}{ccccc}1 & 2 & 3 & 2 & 5 \\ 1 / 2 & 1 & 3 & 2 & 5 \\ 1 / 3 & 1 / 3 & 1 & 1 & 3 \\ 1 / 2 & 1 / 2 & 1 & 1 & 3 \\ 1 / 5 & 1 / 5 & 1 / 3 & 1 / 3 & 1\end{array}\right]$

Weight vector: $\mathrm{W}=(0.3735,0.2831,0.1322,0.1555,0.0557)$

Check the consistency: $\lambda_{\max }=5.1020, \mathrm{CI}=0.0255, \mathrm{CR}=0.0228<0.1$

The second class comparison matrix following:

The second class comparison matrix A1:

$$
\left[\begin{array}{cccc}
1 & 3 & 1 / 2 & 1 / 2 \\
1 / 3 & 1 & 1 / 6 & 1 / 5 \\
2 & 6 & 1 & 3 \\
2 & 5 & 1 / 3 & 1
\end{array}\right]
$$

The second class comparison matrix A2:

$\left[\begin{array}{cccc}1 & 2 & 7 & 2 \\ 1 / 2 & 1 & 5 & 2 \\ 1 / 7 & 1 / 5 & 1 & 1 / 3 \\ 1 / 2 & 1 / 2 & 3 & 1\end{array}\right]$


The second class comparison matrix A3:

$\left[\begin{array}{cccc}1 & 2 & 5 & 3 \\ 1 / 2 & 1 & 3 & 2 \\ 1 / 5 & 1 / 3 & 1 & 1 / 3 \\ 1 / 3 & 1 / 2 & 3 & 1\end{array}\right]$

The second class comparison matrixA4:

$$
\left[\begin{array}{cccc}
1 & 1 / 2 & 1 / 2 & 3 \\
2 & 1 & 1 / 2 & 5 \\
2 & 1 & 1 & 6 \\
1 / 3 & 2 & 2 & 1
\end{array}\right]
$$

The second class comparison matrixA5:

$$
\left[\begin{array}{ccc}
1 & 1 / 3 & 3 \\
3 & 1 & 5 \\
1 / 3 & 1 / 5 & 1
\end{array}\right]
$$

The second class weight vector:

$\mathrm{A} 1: \mathrm{W}(1)=(0.1841,0.0642,0.4845,0.2672)$,

$\mathrm{A} 2: \mathrm{W}(2)=(0.4565,0.2968,0.0620,0.1847)$,

$\mathrm{A} 3: \mathrm{W}(3)=(0.4878,0.2743,0.1259,0.1120)$,

$\mathrm{A} 4: \mathrm{W}(4)=(0.1875,0.3012,0.4459,0.0654)$,

$\mathrm{A} 5: \mathrm{W}(5)=(0.2583,0.6370,0.1047)$

Check the consistency:

$$
\begin{aligned}
& \text { A1 }: \lambda_{\max }=4.1318, \mathrm{CI}=0.0439, \mathrm{CR}=0.0488<0.1 \\
& \text { A2 }: \lambda_{\max }=4.0417, \mathrm{CI}=0.0139, \mathrm{CR}=0.0155<0.1 \\
& \text { A3 }: \lambda_{\max }=4.1763, \mathrm{CI}=0.0588, \mathrm{CR}=0.0653<0.1 \\
& \text { A4 }: \lambda_{\max }=4.0487, \mathrm{CI}=0.0162, \mathrm{CR}=0.0180<0.1 \\
& \text { A5 }: \lambda_{\max }=3.0385, \mathrm{CI}=0.0193, \mathrm{CR}=0.0332<0.1
\end{aligned}
$$

In the first grade indexes, English basis in many influence factors is the most important, if a student has a good foundation in English, then he will have a good self-learning ability and an receiving ability; secondly, teachers with outstanding experiments can teach the knowledge easily, , other teaching method is not so important.

In the second level indicators, writing in English is the most important; in the teachers manning, the teachers with experiences row in the first place; In methods of learning, the students' learning autonomy is the most important; In the teaching contents, teaching goal comes in the first place.

\section{Conclusion}

University Students' English level impact factors are composed of English basis, teacher staff, teaching methods, teaching methods and learning content. In all factors, English basis is the most important. University students have a solid foundation in English, when learning new knowledge; 
can improve efficiency, to get twice the result with half the effort. The teachers have great influence. A good university English teachers have the ability to easily control the teaching material, and according to the specific circumstances, using different teaching methods, to explain in simple terms, can help students to solve the difficulties of learning English and to be enlightened. Compared with the former, teaching methods and learning methods are not particularly important.

\section{References}

[1] Discretion and bias in performance evaluation: the impact of diversity and subjectivity Volume [J]:30, Issue: 1, January, 2005, pp.67-78

[2] http://thequalityportal.com/q_ahp.htm. Retrieved 2007-08-21.

[3] European Management Journal Volume [J]: 21, Issue: 3, June, 2003. pp323-337 